\title{
El enclaustramiento de Bolivia y el factor Argentina*
}

\section{The enclosement of Bolivia and the Argentina factor}

\author{
Pablo Lacoste ${ }^{* *}$ \\ Diego Jiménez Cabrera ${ }^{* * *}$ \\ Instituto de Estudios Avanzados, Universidad de Santiago, Santiago, Chile
}

Recibido: 15 de octubre de 2015. Aprobado: 19 de junio de 2016.

\begin{abstract}
Resumen
Este artículo examina el papel que cupo a Argentina en el enclaustramiento de Bolivia. Se considera tanto su acción durante la Guerra del Pacífico, cuando Bolivia perdió su litoral, como frente a las propuestas chilenas de devolverle salida al mar, tanto en 1895 como en 1975. Se demuestra que Bolivia se acercó a Argentina, esperando obtener ventajas en sus conflictos contra Chile. A su vez, Argentina atrajo a Bolivia a su esfera de influencia para presionar a Chile, pero sin asumir compromisos fuertes con el país altiplánico. Posteriormente, Chile cedió frente a Argentina. Una vez alcanzados sus objetivos, Buenos Aires soltó la mano a Bolivia, que perdió las oportunidades de recuperar su salida al mar. El texto resulta de interés actual debido a la controversia en la Corte Internacional de Justicia (CIJ), organismo ante el cual Bolivia ha demandado a Chile por frustrar las expectativas generadas con las propuestas de salida al mar de 1895 y 1975.

Palabras claves: enclaustramiento de Bolivia, conflicto Bolivia-Chile, política exterior argentina.

\footnotetext{
Una versión anterior de este artículo fue presentada en el XIV Encuentro Boliviano-Chileno de Historiadores, Intelectuales y Cientistas Sociales, Santiago de Chile, 12 al 14 de agosto de 2015. Este trabajo es parte del proyecto ANEPE 201516 "La geopolítica en el cambio de los criterios de delimitación de fronteras marítimas de la Corte Internacional de Justicia: el caso del Cono Sur de América” (2015-2016), financiado por la Academia Nacional de Estudios Políticos y Estratégicos. Santiago. Actualmente es profesor titular del Instituto de Estudios Avanzados de la Universidad de Santiago de Chile. Correo electrónico: pablo.lacoste@usach.cl Internacionales de la misma universidad. Coinvestigador del proyecto ANEPE 201516. Correo electrónico: diego.jimenez.cabrera@gmail.com
}

* Doctor en Historia por la Universidad de Buenos Aires y doctor en Estudios Americanos por la Universidad de

*** Doctorando en Estudios Americanos por la Universidad de Santiago de Chile. Magíster en Estudios
\end{abstract}




\begin{abstract}
The paper examines the role that Argentina had in the enclosure of Bolivia. It considers both its action during the Pacific War, when Bolivia lost its coastline, as during Chilean proposals back out to sea, both in 1895 and 1975. It shows that Bolivia went to Argentina, hoping to gain advantage in their conflicts against Chile. In turn, Argentina drew Bolivia into his influence sphere to pressure Chile, but without assuming strong commitments with that. Subsequently, Chile gave way to Argentina. Once achieved its objectives, Buenos Aires released the hand of Bolivia, which lost the opportunity to recover its access to the sea. The text is of current interest because of the controversy submitted in the International Court of Justice (ICJ), between Bolivia and Chile.
\end{abstract}

Keywords: enclosement of Bolivia, Chile-Bolivia conflict, Argentinian foreign policy.

\title{
Introducción
}

Es un error muy esparcido y que se repite diariamente en la prensa y en la calle, al opinar que Bolivia tiene derecho de exigir un puerto en compensación de su litoral. No hay tal cosa, Chile ha ocupado el litoral y se ha apoderado de él con el mismo título con que Alemania anexó al Imperio la Alsacia y la Lorena, con el mismo título con que los EE.UU. de América han tomado a Puerto Rico. Nuestros derechos nacen de la victoria, la ley suprema de las naciones.

Abraham König, 13 de agosto de 1900

En 2011, el presidente de Bolivia, Evo Morales, anunció que su país demandaría a Chile ante la CIJ para exigir una salida al mar. El fundamento se basaba en que, según Bolivia, después de la guerra del Pacífico, varias veces Chile propuso compensar al país altiplánico con ofertas concretas de salida soberana al mar, que luego se frustraron, como las de 1895 (Arica o caleta Vítor) y 1975-1978 (Charaña) (Inarra, 2011, p. 56; S. Fernández, 2014, p. 182; Estado Plurinacional de Bolivia, 2014, pp. 25-30). Desde la perspectiva de los abogados bolivianos, esas propuestas chilenas fueron actos jurídicos unilaterales que modificaron los tratados. Con estos fundamentos, el Gobierno de Bolivia inició una estrategia política tendiente a presionar a Chile y solucionar su trauma nacional. La idea 
era exigir la reparación, a partir de la impugnación moral de la anexión dispuesta por Chile con el "Memorándum König" de 1900 y el Tratado de 1904.

Desde una perspectiva crítica, se percibe que tanto Bolivia como Chile han abordado el conflicto con enfoques nacionalistas, que tienden a demonizar o minimizar al otro, sin capacidad de diálogo ni de construir alternativas de consenso. Se ha creado así una suerte de enfrentamiento discursivo entre ambas naciones, sin mayores perspectivas de solución política (Molina, 2014a, 2014b). Se hace urgente, entonces, aportar un nuevo enfoque, capaz de superar las miradas nacionalistas. Para avanzar en esta dirección, el presente artículo propone ensanchar el campus político regional mediante la incorporación de un actor central en esta trama que ha sido invisibilizado en los debates: Argentina.

Incluir el factor Argentina en el problema implica visibilizar el papel que cupo al Estado del Plata en este proceso ¿En qué medida el Estado argentino contribuyó a generar y sostener el enclaustramiento boliviano? ¿Cuál fue su papel en la frustración de las propuestas chilenas de 1895 y 1975? Resulta importante despejar esta incógnita para poder comprender mejor el conflicto, pues estos temas constituyen las bases mismas del reclamo boliviano.

\section{Planteamiento del problema}

El enclaustramiento boliviano es un problema grave, tanto para Bolivia como para Chile y la región. Para el país altiplánico es un trauma nacional de profundo significado psicológico, cultural y social. "El mar para Bolivia se ha convertido en la causa y cura de todos sus pesares y un requisito sine qua non para su desarrollo" (S. Fernández, 2014, p. 72). "El enclaustramiento marítimo produjo una transformación profunda que aún hoy afecta la idiosincrasia de los bolivianos" (Molina, 2014b, p.17). Este tema es "una causa nacional” (G. Fernández, 2014, p. 65). "Bolivia cree profundamente que es pobre porque le han quitado el mar” (Brockmann, 2014, p. 79). Para Chile, este problema genera una tensión permanente que, a pesar de algunos intentos por ignorarlo, termina apareciendo una y otra vez en la superficie. Así lo ha reconocido, en su momento, el actual canciller de Chile para quien este país tiene que admitir que el problema del enclaustramiento de Bolivia no es sólo un problema de éste, sino también de Chile (Muñoz, 1989). La persistencia de este problema frustra las expectativas de Chile de afianzar su liderazgo en el Cono Sur y afecta su proyección internacional. Finalmente, para la región, este asunto es una suerte de pozo sin fondo, un manantial inagotable de aguas contaminadas. 
Como un problema regional y bilateral, el enclaustramiento boliviano ha carecido de miradas integrales. Han predominado los enfoques nacionalistas, tanto en Chile como en Bolivia; también se han generado iniciativas de buena voluntad, tendientes a buscar una solución que permita superar el obstáculo (Forteza y Devés, 2006), pero sin examinar crítica ni autocríticamente la causa del conflicto.

El enclaustramiento de Bolivia tiende a perpetuarse por el avanzado proceso de construcción de una actitud hostil entre los países involucrados, particularmente de Bolivia hacia Chile. La literatura especializada elaborada por los intelectuales bolivianos ha conformado, lenta y sostenidamente, un relato que tiende a demonizar a Chile; este país se caracteriza, según esos enfoques, por su tendencia agresiva, expansionista, cínica e imperialista. Un autor califica a Chile de nación "astuta, ambiciosa y poco escrupulosa" (Querejazu, 2010, p. 9). Otro intelectual boliviano tilda el accionar de Chile en términos de "cinismo inaudito", capaz de actuar con "móvil inmoral" (Escobari, 2013, p. 94). Su accionar se evalúa como "monstruoso e impune delito de despojo" (Becerra de la Roca, 2005, p. 16), capaz de "un comportamiento desleal y traidor"; Chile fue "paladín de la agresión" (Becerra de la Roca, 2005, pp. 64 y 66).

Por otra parte, Bolivia "sigue siendo una opinión pública criada, desde la escuela y por un buen siglo ya, en la hostilidad hacia Chile y para la cual Chile es el enemigo y codicioso usurpador" (Brockmann, 2014, p. 84). "En Bolivia el tiempo se ha detenido y vivimos aún el momento de una guerra de hace más de un siglo. El imaginario colectivo boliviano tiene la noción de que Chile es el enemigo" (Salazar, 2006, p. 74). En líneas generales, los analistas bolivianos señalan que Chile es "una nación enemiga que encarna el mal" y "actuar en contra de este enemigo es el camino a la gloria y a alturas legendarias de existencia". Estas palabras se encuadran dentro de lo que los teóricos de la guerra explican acerca de situaciones similares, en las que "cualquiera que no esté de acuerdo con tales verdades es un traidor” (LeShan, 1992, pp. 45-46.)

En la vereda opuesta, Chile exhibe un discurso negatorio de los derechos originales de Bolivia al litoral. Guiados por la idea de justificar la anexión del desierto de Atacama por parte de las fuerzas chilenas en la Guerra del Pacífico, los intelectuales de este país han tendido a sostener que Bolivia carecía de derechos sobre esas tierras y, por lo tanto, Chile nunca la despojó de nada. Para la historiografía chilena, Chile poseía el litoral desde Atacama hasta el límite con Perú; en cambio Bolivia no poseía litoral (Amunátegui, 1863, pp. 71-75; Benavides, 1972, pp. 3-4; Villalobos, 2002, p. 84).

122 Si Somos Americanos. Revista de Estudios Transfronterizos 
La construcción de este discurso nacionalista desde el siglo XIX, tanto en Chile como en Bolivia, en lugar de abrir espacios de diálogo constructivos ha levantado barreras ideológicas infranqueables entre ambos países, dejando únicamente sensaciones de frustración. En Bolivia, la actitud chilena de negar los derechos originales de los bolivianos al litoral es considerada un agravio: "cuando escuchan tal aserto, los bolivianos lo toman a provocación y con vehemencia sacan a relucir argumentos y mapas" (Brockmann, 2014, p. 80). En Chile ocurre lo mismo: causa mala impresión la constante demonización del vecino realizada por historiadores, intelectuales y gobernantes (Salazar, 2006, p. 97; Molina, 2014b, p. 28; Brockmann, 2014, p. 86).

El resultado de estas acciones ha sido crear una profunda antipatía popular. Ello se ha visibilizado en las encuestas de opinión (Salazar, 2006, p. 89). En los últimos años, esta tendencia negativa se ha agravado considerablemente. Si en 2006 el 13\% de la población chilena estaba de acuerdo con ceder una salida soberana al mar para Bolivia, en 2014 ésta cayó al 9\%. De manera inversa, la actitud de no ceder absolutamente nada a Bolivia subió del 33\% en 2006 al 43\% en 2008 y al 58\% en 2014 (El Mercurio, 2014). Éste ha sido el resultado de la estrategia confrontacionista del presidente Evo Morales.

Paradójicamente, el gobierno de Bolivia exige al gobierno de Chile que le ceda una salida soberana al mar. Al parecer, la élite boliviana ha olvidado las palabras de sus más reconocidos prohombres como Rafael Bustillo: "La enajenación del territorio es cosa tan grave que (...) está fuera de las facultades ordinarias del gobierno" (Becerra de la Roca, 2005, p. 164). Ceder territorio nacional es una acción compleja para un gobierno; y mucho más si tiene la oposición del $92 \%$ del pueblo. El rechazo casi unánime del pueblo chileno a la idea de ceder una salida al mar soberana a Bolivia es un problema político serio, pues limita y restringe el margen de maniobra del gobierno de Chile.

Aunque los gobernantes de Chile lo deseen, y el Estado boliviano insista, las autoridades chilenas no pueden conducir la política exterior en una dirección repudiada por su pueblo. Este drama lo vive el actual gobierno de Chile, cuyo canciller, Heraldo Muñoz, en su momento se manifestó en favor de solucionar el problema del enclaustramiento de Bolivia (Muñoz, 1989). Pero no puede aplicar esta política desde el poder, debido a la falta de consenso en las bases sociales. Por este motivo, desde el siglo XX se ha consolidado en Chile un enfoque negador: "la mejor relación con Bolivia es no tener relaciones" (Molina, 2014b, p. 31).

El rechazo del pueblo chileno a darle mar a Bolivia es resultado directo de la constante hostilidad del gobierno boliviano contra Chile. En los últimos años, durante los gobiernos 
de Carlos Mesa y Evo Morales, la política del país altiplánico ha sido guiada por enfoques radicales, lo cual, en lugar de mejorar el ambiente de cordialidad con los vecinos, ha tendido a generar crispación y tensiones. Así lo han admitido expertos bolivianos, como el ex canciller Armando Loayza (Durán, 2014). Desde el plano académico, también se comparte esta autocrítica: "tampoco ayuda la beligerancia de las declaraciones del presidente Morales sobre Chile" (Molina, 2014b, p. 28).

Se ha creado entonces una situación de bloqueo: cada país se ha enroscado en su propia visión nacionalista. Al sostenerse estas posiciones en el tiempo, se ha terminado por construir lo que Clausewitz llama "sentimiento hostil" (Von Clausewitz, 1997, p. 127). Los sucesivos gobiernos de Bolivia han construido una imagen demonizada de Chile, la cual, a través de la escuela, se ha terminado por imponer como ideología dominante en el pueblo boliviano, situación que el diplomático boliviano Armando Loayza ha calificado como la imposición del "irredentismo boliviano". Con este discurso, es posible que Bolivia esté incubando una peligrosa reactivación de las ideologías reivindicacionistas de los geopolíticos europeos de las décadas de 1930 y 1940.

La decisión del Estado Boliviano de demonizar Chile a través de la escuela se ha profundizado últimamente con la decisión del presidente Morales de imponer la lectura de El libro del mar como texto obligatorio en las escuelas (el 23 de marzo de 2015). En Chile, la sociedad ha respondido con una posición nacionalista intransigente. En este contexto, el enclaustramiento de Bolivia parece un problema sin solución, una suerte de oxímoron, o bien, un intento de "cuadrar el círculo" (Molina, 2014b).

Para agravar aún más el bloqueo del conflicto, cada país ha levantado dos principios más que resultan antagónicos entre sí. Por un lado, Chile se ha inclinado varias veces a ceder una salida al mar a Bolivia a cambio de una compensación territorial equivalente. Así se manifestó expresamente, $v$. $g r$., en la propuesta de Charaña. Empero, la posibilidad de ceder territorio a Chile es considerada inaceptable en Bolivia.

Frente a este bloqueo, resulta oportuno abordarlo desde otra perspectiva. El objetivo es examinar el conflicto del enclaustramiento boliviano más allá de la relación bilateral, incorporando el papel que cupo a la Argentina, desde una mirada crítica. Así, el objetivo final es entregar una nueva perspectiva que estimule el análisis autocrítico en ambos países y a la vez abra el camino para encontrar otras soluciones.

124 Si Somos Americanos. Revista de Estudios Transfronterizos 


\section{Argentina y la "Cuestión del Pacífico" (1873-1881)}

En 1873, Bolivia y Perú firmaron el tratado secreto de alianza militar, con expresa voluntad de sumar a Argentina. Este proyecto se consideraba probable, dado que esta tercera nación tenía pendiente con Chile la definición de la soberanía sobre la Patagonia $\left(1.000 .000 \mathrm{de} \mathrm{km}^{2}\right)$. En 1856, Argentina y Chile habían firmado un tratado por el cual se comprometieron a resolver sus fronteras a partir del uti possidetis iuris de 1810. Empero, la Patagonia (igual que el desierto de Atacama) no fue colonizada por los españoles en el período colonial. Por este motivo, las delimitaciones administrativas del imperio eran poco conocidas y había incertidumbre sobre el contenido de los documentos de prueba. Ante las dificultades de resolver el pleito por medio de los títulos jurídicos, no se descartaba la solución mediante la guerra. Por este motivo, Bolivia y Perú consideraban que Argentina podía interesarse por suscribir el Tratado Secreto de 1873. Con este objetivo mandaron al peruano Manuel de Yrigoyen a Buenos Aires a obtener el apoyo argentino.

Argentina negoció su incorporación al Tratado Secreto de 1873 durante tres años. En setiembre de 1873 el poder ejecutivo resolvió adherir al tratado (Yrigoyen, $1921 \mathrm{p}$. 93). El presidente Sarmiento lo remitió al Congreso y en sesión secreta de septiembre de ese año la Cámara de Diputados lo aprobó por 48 votos a favor y 18 en contra. Se abrió, entonces, una nueva negociación para obtener el consenso del Senado. Diversos puntos menores dilataron su tratamiento, pero la media sanción dada en la Cámara de Diputados mantuvo la tensión en los años siguientes (Gutiérrez, 2012, pp. 270-296; Villalobos, 2002, pp. 104-105). En 1878, los blindados chilenos se desplegaron en el Atlántico Sur y reivindicaron los derechos chilenos sobre la Patagonia oriental, apoyados jurídicamente en las Reales Cédulas del siglo XVI y el principio del uti possidetis iuris. La firma del tratado Fierro-Sarratea, en diciembre de 1878, determinó el sometimiento de la totalidad de la Patagonia al arbitraje, el cual sería ganado por Chile. ${ }^{1}$ Dos meses después estalló la Guerra del Pacífico, y Argentina hizo una prueba elocuente de realismo político, al aprovechar la circunstancia para soltar definitivamente la mano a Bolivia y negociar con Chile el Tratado de Límites de 1881, por el cual anexó gran parte de la Patagonia: $1.000 .000 \mathrm{de} \mathrm{km}^{2}$. Mientras tanto, Bolivia, abandonado a su suerte, se enfrentó a la tragedia: "Bolivia perdió más que territorio $\left(126.000 \mathrm{~km}^{2}\right)$ y riquezas mineras. Quedó

En 1878 no se había descubierto todavía la Real Cedula de 1570 por la cual la Corona había extendido la jurisdicción de la gobernación de Buenos Aires hasta cerca del Estrecho de Magallanes. En cambio, sí se conocían las reales cédulas del siglo XVI que otorgaban a Chile títulos sobre la Patagonia. Por este motivo, en caso de realizarse el arbitraje, a la luz del principio de uti possidetis iuris de 1810, Chile hubiera ganado la totalidad de la Patagonia (Lacoste, 2003). 
encerrada detrás de la cordillera de los Andes, sin cualidad marítima y dependiente para su desarrollo de los puertos de Chile” (G. Fernández, 2014, p. 49).

\section{De Estanislao Zeballos al “Memorándum König”}

El segundo episodio se produjo en 1895, en oportunidad de la entrega de la propuesta chilena a Bolivia que concedía una salida al mar después del plebiscito con Perú. Por el tratado Barros-Gutiérrez, Chile formuló a Bolivia una propuesta por la cual le aseguraba salir del enclaustramiento, sea cual fuere el resultado del plebiscito establecido en el Tratado de Ancón (1883), por el cual los pueblos de Tacna y Arica debían expresarse para definir si volvían a incorporarse a Perú o si se mantendrían dentro de Chile.

Conforme al tratado del 18 de mayo de 1895, si Chile ganaba el plebiscito, cedería Tacna y Arica a Bolivia. En caso contrario, Chile cedería a Bolivia el territorio inmediatamente al sur, desde la Caleta Vítor hasta la de Camarones. El acuerdo fue firmado por los cancilleres Heriberto Gutiérrez (Bolivia) y Luis Barros Borgoño (Chile) (Lagos, 1981, p. 84; S. Fernández, 2014, pp. 58-59). Posteriormente fue perfeccionado por el Protocolo del 9 de diciembre de 1895, en el cual se emplazaba a Chile a ceder la salida al mar a Bolivia en un plazo máximo de dos años. Además, se estableció que el territorio cedido por Chile debía satisfacer las necesidades presentes y futuras de Bolivia, dejando su ponderación a criterio de este último (Carrasco, 1990, p. 112).

Estos acuerdos de 1895 son claves para el actual pleito de ambas naciones ante la Corte Internacional de Justicia (CIJ), pues se trata de uno de los antecedentes invocados por Bolivia para sostener su posición de reivindicar los "derechos expectaticios" generados por Chile con sus ofertas de salida al mar (Estado Plurinacional de Bolivia, 2014, p. 25). Con estos acuerdos, Bolivia tenía en sus manos la solución concreta para salir de su enclaustramiento. Pretendía de este modo iniciar un camino que debía conducir al retorno del país altiplánico al Pacífico, por lo que se crearon grandes expectativas de solucionar el conflicto.

Finalmente, el proyecto se frustró. El libro del mar se limita a sostener que Chile no cumplió con este compromiso asumido en mayo de 1895, sin explicar lo que ocurrió (Estado Plurinacional de Bolivia, 2014, p. 25). Y eso es lo que conviene examinar ahora. 
En las negociaciones de 1895, Bolivia lograba una salida al mar, a la vez que reconocía a Chile la soberanía sobre los territorios de Atacama, conquistados en la Guerra del Pacífico. Ello incluía la Puna de Atacama, tal como se había estipulado en el tratado Reyes-Matta, suscrito en La Paz el 19 de mayo de 1891 (Corbacho, Corigliano, Machinandiarena de Devoto, González de Oleaga y Tedesco, 1999, p. 36). Ése era el quid pro quo de los acuerdos diplomáticos entre estos dos países.

Sin embargo, simultáneamente, y sin informar a Chile, Bolivia utilizó parte de esos mismos territorios para negociar con Argentina. Éste fue el sentido de los tratados Quirno Costa-Vaca Guzmán (Buenos Aires, 10 de mayo 1889) y Cano-Rocha (Sucre, 12 de diciembre de 1895), a través de los cuales Bolivia cedió a Argentina los derechos sobre la Puna de Atacama a cambio de la soberanía definitiva sobre Tarija. En otras palabras, Bolivia ofreció simultáneamente el mismo espacio a dos países distintos, tratando de obtener ventajas de cada uno. Al parecer, los diplomáticos bolivianos no advirtieron a tiempo que sería imposible cumplir a la vez con las dos contrapartes. La historiografía argentina ha explicado este fenómeno en los siguientes términos:

La actitud de la diplomacia boliviana respecto la cuestión de la Puna de Atacama fue la de ofrecerla simultáneamente a los gobiernos de la Argentina y Chile, procurando con este doble juego extraer las máximas ventajas posibles de sus dos poderosos vecinos -ventajas tales como, por ejemplo, obtener el territorio de Tarija de la Argentina y la salida al Pacífico de Chile. (Corbacho et al., 1999, p. 146).

El documento decisivo de este proceso fue el protocolo firmado en Sucre, el 12 de diciembre de 1895, entre el embajador Dardo Rocha y el canciller boliviano Emeterio Cano. Era evidente que Bolivia no tenía posesión real de la Puna, pues ese territorio fue conquistado por Chile durante la Guerra del Pacífico, ocupado desde 1887 y gobernado a partir de entonces (Espinosa, 1958, p. 108). De todos modos, esos títulos podían ser de utilidad para Buenos Aires si se acompañaban de poder militar y diplomacia activa. Además, dentro del bloque de poder rioplatense, este acuerdo servía a los intereses de los halcones, liderados por Estanislao Zeballos. ${ }^{2}$ En los hechos, este tratado representaba

2 "La culpa de que la cuestión de la Puna asuma un carácter agrio la tiene el señor Estanislao Zeballos, que, sabiendo que Chile estaba en posesión de ella y la tenía incorporada por ley dentro de su provincia de Antofagasta, prefirió tratar a solas con Bolivia y convenir en su transferencia a la República Argentina, a espaldas de Chile y en ignorancia de éste. Si el derecho de Bolivia a la Puna es tan claro e incuestionable ¿por qué no se invitó a Chile a concurrir a aquellas negociaciones? ¿Acaso el asunto estaría hoy amistosamente solucionado” (Oficio de Morla Vicuña a Juan José Latorre, 23 de septiembre de 1898). (Citado en Espinosa, 1958, p. 108). 
una reactualización del Tratado Secreto de 1873, y brindó grandes esperanzas a los altos mandos de las fuerzas armadas de Bolivia.

La seductora misión Rocha en Bolivia fue acompañada por un conjunto de medidas concretas a través de las cuales Buenos Aires se inclinaba a asumir un papel activo en los conflictos del Pacífico. El antecedente más relevante se había registrado durante la segunda gestión de Estanislao Zeballos como canciller (1891-1892). En el marco del incidente del Baltimore, que estuvo a punto de generar un conflicto militar entre Chile y EE.UU., Zeballos expresó su respaldo a este último, al que ofreció información de inteligencia y suministros en caso de eventual invasión al norte de Chile (Barros, 1963; Corbacho et al., 1999, pp. 20-21). Paralelamente, Zeballos impulsó la mayor carrera armamentista de la historia argentina. Un hito clave fue la incorporación del acorazado 25 de mayo (1891), al cual siguió el 9 de julio (1892). Así, la flota de guerra argentina se transformaba, de reserva defensiva fluvial, en poder marítimo. Esta tendencia se profundizó con la firma del tratado Cano-Rocha, el que abrió el camino al crecimiento del poder marítimo argentino.

Pocos días después de aquel tratado, los días 8 y 11 de enero de 1896, la Cámara de Diputados argentina aprobó la autorización de 14 millones de pesos oro para la compra de acorazados en la casa Ansaldo de Italia (Espinosa, 1958, p. 129). La flota de guerra de Argentina incrementó sus capacidades con la incorporación de los acorazados Buenos Aires y Garibaldi (1896), San Martín (1897), Belgrano y Pueyrredón (1898). A ello se sumaron los destructores Santa Fe y Misiones (1896), Entre Ríos y Corrientes (1897). Además, por la ley 3.450 del 30 de noviembre de 1896, el Congreso aprobó nuevos fondos para la construcción de un puerto militar. Entre 1895 y 1898 las capacidades navales de Argentina subieron de 24.946 a 43.078 toneladas métricas (Corbacho et al., 1999, p. 44-45). De esta manera se fue creando un clima de hostilidad en el Cono Sur. Dentro de este proceso de carrera armamentista, el Protocolo Cano-Rocha fue un complemento diplomático de singular importancia. Así lo ha señalado un historiador boliviano, para quien el acuerdo mencionado "casi lleva a la guerra a ambos países. Bolivia contaba con este hecho y su posible alianza con Argentina” (S. Fernández, 2014, p. 65).

La firma del Protocolo Cano-Rocha y el ambiente de sintonía entre Argentina y Bolivia generaron un nuevo clima en las relaciones entre Bolivia y Chile. El negociador boliviano se sintió empoderado por la eventual alianza con Argentina, por lo que endureció su posición contra Chile. Ello se reflejó en el Protocolo Aclaratorio firmado en Santiago el 30 de abril de 1896 por el canciller chileno, Adolfo Guerrero Vergara, y el ministro plenipotenciario de Bolivia, Heriberto Gutiérrez. Este documento abordaba diversas 
materias y establecía nuevas condiciones para viabilizar los acuerdos alcanzados en 1895 . El punto saliente fue la decisión por la cual se establecía que "la falta de aprobación de uno de los congresos del protocolo del 9 de diciembre o su aclaración hecha importaría un desacuerdo sobre la base fundamental de los pactos de mayo (de 1895) que los haría ineficaces en su totalidad" (Carrasco, 1990, p. 113). Posteriormente, la gradual incorporación de buques de guerra a la marina argentina tendió a incrementar la actitud optimista de la élite boliviana y a endurecer sus posturas frente a Chile. Ello se reflejó en diciembre de 1896, cuando el parlamento de Bolivia declaró la necesidad de revisión de la caleta (Caleta Vítor) que Chile le cedería, pues ésta no reunía las condiciones económicas adecuadas. "Esto era, lisa y llanamente, volver a fojas cero" (Barros, 1963, p. 535).

La diplomacia chilena se vio en una situación de asedio con dos frentes abiertos. Al endurecimiento de las actitudes de Bolivia, se sumó la nueva exigencia de la diplomacia argentina. La firma del Protocolo Cano-Rocha había dado a Buenos Aires el sustento que necesitaba para llevar adelante la ofensiva diplomática contra Chile. El gobierno argentino exigió a Chile el reconocimiento de los derechos sobre la Puna de Atacama. Esta vez, la posición de Buenos Aires podía exhibir títulos jurídicos y fuerzas militares renovadas.

De todos modos, las expectativas de los sectores belicistas de Bolivia y de Argentina se vieron frustradas. El conflicto trasandino se decantó hacia la solución negociada: no hubo guerra entre Argentina y Chile, sino una solución pacífica. El 24 de marzo de 1899, el Laudo Buchanan cedió $64.000 \mathrm{~km}^{2}$ a Argentina (85\%) y 11.000 a Chile (15\%). De esta manera se cerró el proceso formalizado con el Protocolo Cano-Rocha de 1895. Argentina terminó por incorporar un amplio territorio a su soberanía. Cumplida su misión, la diplomacia argentina se replegó nuevamente hacia el Plata, renunciando a la lucha del poder en el Pacífico. Así se estableció en los Pactos de Mayo (1902). El significado de este tratado fue que Argentina soltó la mano de Bolivia nuevamente.

Lo que para Argentina fue una diversión táctica para ensanchar su territorio soberano, para Bolivia fue muy diferente. En efecto, la decisión de firmar el Protocolo Cano-Rocha tuvo un efecto negativo en las relaciones entre Bolivia y Chile. La historiografía chilena ha señalado con claridad el impacto que produjo en Santiago la noticia del acuerdo Cano-Rocha, una vez publicada por la prensa argentina: "El canciller Guerrero llamó al ministro boliviano Gutiérrez y le explicó que, ante las actuales circunstancias, los tres protocolos quedaban en la nada" (Barros, 1963, p. 535). Por su parte, la historiografía argentina también ha registrado esta tensión: "La cancillería chilena reaccionó contra el Protocolo Cano-Rocha y elevó su protesta al ministro boliviano en Santiago, sosteniendo 
que Bolivia había concedido a la Argentina un territorio del cual Chile era el legítimo propietario" (Corbacho et al., 1999, p. 38).

El territorio perdido por Chile equivalía a la suma de las actuales regiones de Valparaíso, Maule y Bío Bío. Al aceptar ese acuerdo, Bolivia agravió a Chile y lo colocó en una posición bochornosa. Chile evitó la guerra contra Argentina, pero a un alto costo. Chile sufrió como una humillación la pérdida de la Puna, y la soportó en silencio frente a los diplomáticos argentinos. Pero esa frustración se canalizaría en las negociaciones con Bolivia.

El Protocolo Cano-Rocha significó para Chile la pérdida de la mayor parte de la Puna, pero al mismo tiempo provocó la frustración de la propuesta de salida al mar para Bolivia, firmada en mayo de 1895. Así lo ha reconocido la intelectualidad boliviana, al admitir que el Protocolo Cano-Rocha "enfadó [a Chile] y perjudicó las negociaciones bilaterales" (S. Fernández, 2014, p. 62), perdiéndose de este modo la confianza entre Chile y Bolivia (Jeffs, 2014, p. 99). "Chile cierra la posibilidad de negociar un puerto para Bolivia; ya no estaba dispuesto a ceder territorio y, por ello, acredita en La Paz como ministro plenipotenciario a Abraham König" (S. Fernández, 2014, p. 65). La visión es compartida también en Chile: "la actitud boliviana en el problema de la Puna de Atacama y sus exigencias posteriores fueron determinantes en el fracaso de las negociaciones chileno-bolivianas" (Carrasco, 1990, p. 114).

La figura de König ingresó en el centro del escenario de las relaciones entre Chile y Bolivia como resultado de este proceso. En cierta forma, el "Memorándum König", por el cual Chile anunció su decisión de cancelar los proyectos de conceder una salida al mar a Bolivia, se comenzó a redactar en el despacho del canciller argentino Estanislao Zeballos. La firma de los Pactos de Mayo (1902) abrió el camino al Tratado de Límites entre Chile y Bolivia (1904).

\section{Entre Charaña y el canal Beagle}

La firma de los Pactos de Mayo inauguró un largo período de paz entre Argentina y Chile. Muchos buques de guerra se revendieron a grandes potencias y sirvieron en conflictos del hemisferio norte, como la guerra ruso-japonesa (1905) y la Primera Guerra Mundial. Argentina se dio por satisfecha con los territorios ganados y durante un largo 
período de tiempo no volvieron a surgir conflictos. Esta situación cambió con motivo del laudo arbitral de las islas del canal de Beagle (1977), proceso que reactivó la tradición nacionalista argentina y la escuela de Estanislao Zeballos, liderada en ese entonces por geopolíticos como Osiris Villegas, los historiadores de la Academia Nacional de la Historia y los halcones del gobierno militar (almirante Emilio Massera, general Luciano Benjamín Menéndez, entre otros). Se desencadenó entonces un nuevo proceso de hostilidad trasandina, el cual coincidió cronológicamente con la propuesta de Charaña entre Chile y Bolivia. Nuevamente, la política exterior argentina se iba a cruzar con el problema del enclaustramiento boliviano.

La oferta de una salida al mar propuesta por Augusto Pinochet a Bolivia en 1975 es otro de los antecedentes invocados por Evo Morales en la demanda contra Chile en la CIJ por "derechos expectaticios" (Estado Plurinacional de Bolivia, 2014, pp. 29-30). Igual que en 1895, Argentina tuvo un papel relevante en estas negociaciones; esta vez lo que estaba en juego no era la Puna de Atacama, sino las islas del canal Beagle y los mares australes.

La nueva propuesta de salida al mar para Bolivia se formalizó el 8 de febrero de 1975, en la estación ferroviaria de Charaña, en el marco del encuentro entre los presidentes Pinochet y Banzer. Allí se firmó la declaración conjunta para la cual se iniciaban las negociaciones tendientes a ceder una salida al mar para Bolivia. A partir de entonces se realizaron una serie de reuniones, encuentros e intercambios de notas entre las autoridades de ambos países y de Perú, que era parte involucrada de acuerdo con el Tratado de 1929. Como era de esperar, las tratativas no fueron fáciles; por un lado, Bolivia se oponía a ceder territorios compensatorios a Chile; por otra, Perú cuestionó la idea original y formuló su propia propuesta.

El debate se prolongó durante tres años, y tuvo la participación de intelectuales y especialistas, juntamente con la opinión pública a través de los medios de comunicación. Perú demoró 11 meses en contestar la consulta y entregar su contrapropuesta. El 23 de noviembre de 1977, el presidente Pinochet escribió a su par de Bolivia para renovar la decisión de encontrar una solución al enclaustramiento de Bolivia. El presidente Banzer respondió el 21 de diciembre, para avanzar en esa dirección. El 18 de enero de 1978, Pinochet contestó con una nueva carta, que mantenía viva la negociación. El 10 de marzo, el enviado confidencial del presidente Banzer, Wily Vargas Vacaflor, sostuvo dos entrevistas con el canciller chileno, Patricio Carvajal. El tema ha sido examinado por la bibliografía especializada (Carrasco, 1990, pp. 279-299; S. Fernández, 2014, pp. 107129). Empero, el 17 de marzo de 1978, Bolivia anunció que cancelaba las negociaciones y rompía relaciones diplomáticas con Chile. 
En el relato oficial de Bolivia, la propuesta de Charaña se frustró exclusivamente por decisión de Chile (Estado Plurinacional de Bolivia, 2014, pp. 29-30). Sin embargo, un análisis más profundo de los hechos muestra algo diferente.

El motivo de la decisión de Bolivia estaba, una vez más, en Argentina. El conflicto del Beagle, iniciado en 1915, culminó con el Laudo Arbitral Internacional del 1 de mayo de 1977, en plenas negociaciones entre Chile y Bolivia por la salida al mar. El laudo había otorgado a Chile las tres islas en disputa y la soberanía sobre el mar, desde el canal de Beagle hacia el sur. Acorde con los compromisos contraídos, el fallo era inapelable y obligatorio para las partes. El laudo fue inmediatamente aceptado por el gobierno chileno, no así por el argentino. En vez de acatarlo, el gobierno militar de Buenos Aires inició un movimiento de acercamiento hacia sus pares de Bolivia y Perú, con vistas a tantear un posible entendimiento. Se realizaron consultas y encuentros al más alto nivel entre autoridades de los tres países, a la vez que se enfriaban las relaciones con Chile. Finalmente, el 25 de enero de 1978 el gobierno militar argentino anunció que declaraba nulo el laudo arbitral. Luego, el 17 de marzo de 1978, el gobierno boliviano rompió relaciones diplomáticas con Chile, en solidaridad con la posición argentina. Para comprender el estado de las relaciones entre Argentina y Bolivia, resulta esencial revisar el estado del vínculo argentino-boliviano en el período 1975-1978 a nivel político.

En primer lugar, cabe señalar que las relaciones entre ambos países adquirieron un considerable nivel de desarrollo en paralelo al Acuerdo de Charaña. Por ejemplo, ambos países suscribieron el 2 de abril de 1975 un convenio administrativo de cooperación entre las respectivas fuerzas aéreas, el que contempló la cooperación en mantenimiento de cazas bombarderos Sabre F-86-F y el proceso de asistencia técnica e instrucción de cuadros de la fuerza aérea argentina a la boliviana (Biblioteca Digital de Tratados del Ministerio de Relaciones Exteriores y Culto de Argentina, 2 de abril de 1975, p. 1). Esta alianza se desarrolló dentro de una robusta agenda conjunta que contemplaba acuerdos en materia energética, integración física, protección conjunta de parques fronterizos, entre otros.

Los acuerdos señalados se vieron sistemáticamente reforzados y actualizados por cinco declaraciones conjuntas de carácter vinculante en el período 1976-1978. Un tema presente en todas ellas fue la mediterraneidad boliviana, sobre la cual Argentina y Bolivia se pronunciaron inicialmente en los siguientes términos:

Coinciden en reafirmar, tal como se expresara en la declaración presidencial conjunta suscrita en Buenos Aires el 15 de noviembre de 1973, que la situación de mediterraneidad que afecta a Bolivia constituye un factor limitante para su

\section{Si Somos Americanos. Revista de Estudios Transfronterizos}


desarrollo que disminuye la eficacia del proceso de integración de América Latina. Con respecto a esta materia el Canciller argentino manifiesta una vez más la complacencia de su Gobierno por los avances logrados y expresa su confianza en que las negociaciones en curso permitirán alcanzar un arreglo satisfactorio para todas las partes involucradas, resultando una solución efectiva para el actual enclaustramiento de Bolivia. (Biblioteca Digital de Tratados del Ministerio de Relaciones Exteriores y Culto de Argentina, 16 de marzo de 1976, p. 4)

La referencia anterior se señaló en dos declaraciones presidenciales conjuntas de Argentina y Bolivia entre 1975 y 1978 (Biblioteca Digital de Tratados del Ministerio de Relaciones Exteriores y Culto de Argentina, 30 de octubre de 1976, p. 3; Biblioteca Digital de Tratados del Ministerio de Relaciones Exteriores y Culto de Argentina, 8 de julio de 1976, p. 3). Como se puede observar, el apoyo argentino a Bolivia fue expresado en términos relativos, por no pronunciarse Argentina sobre el contenido ni el alcance de la solución, más allá de que ésta resultase satisfactoria para todas las partes en controversia.

No obstante, el gobierno argentino, una vez publicado el rechazo al laudo arbitral y fracasado el Acuerdo de Charaña, comenzó a movilizar sus fuerzas armadas hacia las fronteras con Chile, a la vez que incrementaba su producción de armamento. Para satisfacer la creciente demanda de sus fuerzas armadas nacionales, el director de Fabricaciones Militares, general Diego Ernesto Urricarit, anunció que la institución estaba incrementando su esfuerzo en la producción de material bélico (Los Andes, 1978, 29 de julio).

La flota naval argentina realizó preparativos para demostrar su poder en el Atlántico Sur. El buque insignia era el portaviones 25 de mayo, el cual realizó intensos ejercicios de entrenamiento diurno y nocturno. Los buques de guerra, desde sus bases de Puerto Belgrano, y los submarinos, desde sus apostaderos en Mar del Plata, realizaron maniobras para familiarizar a sus oficiales y tripulantes con el teatro de operaciones del Atlántico Sur. El 17 de diciembre, un avión espía chileno avistó al portaviones 25 de mayo, el crucero General Belgrano y otros nuevos destructores de la flota de mar rioplatense en posiciones amenazantes (Arancibia y Bulnes, 2014, pp. 204 y 138).

En Chile, el gobierno trabajaba con la Hipótesis Vecinal 3 (HV3), es decir, una guerra a tres frentes. Por tercera vez se planteaba la probabilidad de la alianza de los tres países juntos contra Chile, tal como se había intentado en el Tratado Secreto de 1873. El gobierno nacional llamó a la reinscripción a los reservistas nacidos entre 1947 y 1956: 100.000 
hombres debieron actualizar sus datos para ser convocados en caso de movilización (Los Andes, 1978, 5 de abril, p. 2).

La flota de guerra de Chile se preparó durante todo 1978 para entrar en combate. Se realizaron varios viajes de entrenamiento al teatro de operaciones sur, con el personal en puestos de combate; se practicaron evoluciones y maniobras. El crucero Latorre fue reparado a marchas forzadas en los astilleros de Talcahuano, para integrar la sección misilística de la flota chilena, junto con los destructores Williams y Riveros y las fragatas misilísticas Lynch y Condell. Paralelamente, se movilizaron también los buques artillados: el crucero Prat (buque insignia) y los destructores Cochrane, Blanco, Zenteno y Portales. También se movilizaron hacia el sur los submarinos Simpson, O’Brien y Hyatt, el petrolero Araucano, y otros 18 buques anfibios y auxiliares.

Tras realizar sus maniobras en el sur, la flota de guerra chilena regresaba al puerto de Valparaíso, donde permaneció en estado de alerta (Arancibia y Bulnes, 2014, p. 105). El ambiente estaba cargado de agresividad en la región. El clima de guerra crecía, y la participación de Bolivia se hacía cada vez más evidente. Los primeros días de abril se registraron incidentes en la frontera entre Chile y Bolivia (Los Andes, 1978, 7 de abril, p. 4).

Para coordinar la futura acción entre Argentina y Bolivia, el canciller del Plata visitó La Paz a fines de ese mes (Los Andes, 1978, 20 de abril, p. 1). Como resultado de ese encuentro, el gobierno de Bolivia dio a conocer una declaración de respaldo a la posición argentina en "defensa de la integridad territorial". Así lo expresó su canciller, el general de aviación Óscar Adriazola. Para fortalecer la imagen de sintonía entre Argentina y Bolivia, se firmaron varios convenios (Los Andes, 1978, 21 de abril, p. 2; 1978, 22 de abril, p. 2). Dentro de este juego de emitir señales de alianza, Bolivia reivindicó su salida al mar, y el gobierno argentino expresó su respaldo a esa proclama en dos declaraciones conjuntas (Biblioteca Digital de Tratados del Ministerio de Relaciones Exteriores y Culto de Argentina, 8 de julio de 1978, pp. 2-3; Biblioteca Digital de Tratados del Ministerio de Relaciones Exteriores y Culto de Argentina, 25 de octubre de 1978, p. 3), de las cuales la primera se emitió un mes después del fracaso de las negociaciones de Charaña.

Posteriormente, el escenario de la sintonía entre Bolivia y Argentina se trasladó a Mendoza, con la visita del comandante en jefe del ejército boliviano. En los actos oficiales se volvió a reivindicar la salida al mar para Bolivia (Los Andes, 1978, 18 de mayo, p. 7). Para enardecer aún más el ambiente, durante su visita a la Argentina, el comandante del ejército de Bolivia, general Alfonso Villalpando, acusó a Chile de usurpar su litoral

\section{Si Somos Americanos. Revista de Estudios Transfronterizos}


Pacífico. Chile respondió que Bolivia recuperaría su salida al mar con diálogo y "no con una campaña antichilena" (Los Andes, 1978, 21 de mayo, p. 5). Tres meses después, el gobierno de Bolivia llamó a la unidad nacional porque "sobre el Cono Sur del continente, el espectro de la guerra otra vez proyecta su fatídica sombra”. Luego añadió que Bolivia podía verse involucrada en ese conflicto debido a su "situación geopolítica" (Los Andes, 1978, 24 de agosto, p. 4).

Poco después, el 27 de agosto de 1978, el matutino El Diario de La Paz, publicó un artículo de guerra-ficción en el que se narraba el comienzo del conflicto con la invasión de tanques chilenos a la Patagonia argentina; luego, los aliados reaccionaban: los blindados argentinos cortaban las líneas de comunicaciones de las fuerzas chilenas; el ejército boliviano invadía el norte de Chile; la aviación peruana bombardeaba Santiago, Pinochet se suicidaba y Chile se rendía. Este artículo se publicó posteriormente en la prensa de Chile y Argentina: en El Mercurio, en su edición del 10 de septiembre de 1978, y en Los Andes, en su edición del 14 de septiembre de 1978 (pp. 1 y 3).

El gobierno argentino llegó efectivamente a poner en marcha los mecanismos para iniciar la guerra contra Chile. Se realizaron desplazamientos de tropas y material bélico hacia las fronteras y la zona austral, tanto del Ejército como de la Marina y la Fuerza Aérea. De la base naval de Usuahia entraban y salían buques de guerra, registrándose una constante actividad (Tapia, 1997, p. 71). Entre septiembre y diciembre de 1978, la mayor parte de la población civil de Usuahia fue evacuada hacia Buenos Aires (Tapia, 1997, p. 80). En Río Gallegos se concentraron 15.000 tropas y 200 tanques, vehículos blindados y piezas antiaéreas (Arancibia y Bulnes, 2014, p. 198).

Los medios de prensa argentinos coincidieron en fomentar un ambiente prebélico, propio de las vísperas de una guerra (Lacoste, 2001, pp. 101-107). El gobierno contribuía a este clima con medidas de alto impacto, como el apagón de Buenos Aires, ocurrido el 24 de octubre de 1978 (Arancibia y Bulnes, 2014, p. 137) y la suscripción en la ciudad boliviana de Yacuiba, el 25 de octubre de 1978, de una declaración conjunta con Bolivia que se pronunciaba sobre el enclaustramiento de esta última en los términos expresados a continuación:

3. El Presidente de Bolivia agradeció el permanente apoyo del Gobierno y pueblo argentinos para superar el enclaustramiento geográfico que retarda desde hace casi un siglo el desarrollo económico y social de su país. 
Por su parte, el presidente de la Argentina ratificó, una vez más, el firme y decidido apoyo de su país a la justa aspiración boliviana de obtener un acceso soberano al Pacífico.

El presidente de la Argentina reiteró la decisión de su Gobierno de otorgar a Bolivia facilidades para su vinculación natural con el Atlántico, a través de territorio argentino; vinculación que, además de aliviar en parte la mediterraneidad que afecta a Bolivia, significa el reconocimiento del papel que a ésta le corresponde en el sistema de la Cuenca del Plata.

4. El Presidente argentino ratificó ante el Presidente de Bolivia la indiscutible jurisdicción que la República Argentina ejerce en el Atlántico suroccidental. Asimismo, reafirmó el derecho de su país a ejercer soberanía sobre las Islas Malvinas, conforme a los principios jurídicos y derechos históricos que la sustentan [...]

[...] El Presidente de Bolivia, reiterando los principios que sostiene su país relativos al respeto a la integridad territorial y a la preservación del patrimonio geográfico de las Naciones Americanas, expresó el reconocimiento y respaldo de su Gobierno a las reivindicaciones que, en un plano de entendimiento, defiende la República Argentina. (Biblioteca Digital de Tratados del Ministerio de Relaciones Exteriores y Culto de Argentina, 25 de octubre de 1978, pp. 3-4).

De este modo, ambos países sustentaban sus respectivas proclamas territoriales. Por una parte, Argentina brindó un apoyo acérrimo a la aspiración soberana al Pacífico de Bolivia y comprometió las medidas necesarias para la integración boliviana a la Cuenca del Plata. Al mismo tiempo, Bolivia respaldó la demanda argentina sobre las islas Picton, Nueva y Lennox, al referirse el gobierno argentino al "Atlántico suroccidental". Esto último, sumado a la suscripción de un acuerdo sobre el estudio conjunto de los usos pacíficos de la energía nuclear, el 21 de abril de 1978 en La Paz, cuyos estudios por comisión mixta quedaron comprometidos para marzo de 1979 (Biblioteca Digital de Tratado del Ministerio de Relaciones Exteriores y Culto de Argentina, 25 de octubre de 1978, pp. 9-10), llevó a un nivel de interacción tal entre ambos países que amenazó con dejar vulnerable a Chile. Estas asimetrías en los niveles de cooperación pueden ser apreciadas en la Tabla 1: 
Volumen XVI / Nº 1 / enero-junio 2016 / pp. 119-145

Tabla 1

Documentos bilaterales Argentina-Chile y Argentina-Bolivia en tres periodos

\begin{tabular}{cccccccccccc}
\hline \multirow{1}{*}{$\begin{array}{c}\text { Contra- } \\
\text { parte de }\end{array}$} & \multicolumn{1}{c}{ Período de análisis } & \multicolumn{1}{c}{ TOTAL } \\
Argentina & $1873-1881$ & $\%$ & M & $\begin{array}{c}1895- \\
1902\end{array}$ & $\%$ & M & $\begin{array}{c}1975- \\
1978\end{array}$ & $\%$ & M & \\
\hline Chile & 6 & 10,52 & 0,66 & 31 & 54,39 & 3,88 & 24 & 35,09 & 6 & 61 \\
Bolivia & 4 & 8,51 & 0,44 & 10 & 21,28 & 1,25 & 39 & 70,21 & 9,75 & 53 \\
\hline Total & 10 & 9,62 & & 41 & 39,42 & & 63 & 50,96 & & 114 \\
\hline
\end{tabular}

Fuente: elaboración propia a partir de la base de datos de la Biblioteca Digital de Tratados del Ministerio de Relaciones Exteriores y Culto de Argentina.

Nota: $\mathrm{M}=$ Media.

Por otra parte, del lado chileno, las medidas preventivas también llamaban la atención del público, sobre todo cuando se acondicionó el Metro de Santiago como refugio antiaéreo. El 14 de diciembre, Pinochet ordenó la movilización de las fuerzas armadas. Para entonces, el Ejército llegó a tener 125.000 efectivos (Arancibia y Bulnes, 2014, pp. 196-197).

La mayor parte de la documentación oficial referida a la decisión de iniciar la guerra se ha mantenido en secreto por razones de seguridad nacional. Pero algunos documentos se han filtrado por otros medios. Por ejemplo, el entonces embajador argentino en Brasil, Óscar Camilión, lo ha señalado en sus memorias:

Yo recibí en el transcurso de mi estada en Brasil el fatídico telegrama del 20 de diciembre de 1978 que me daba instrucciones en 24 horas para cumplir 48 horas después, informándole a Itamaraty que en ese momento se estaba produciendo el ataque de las Fuerzas Armadas argentinas a Chile. (Camilión, 2000, p. 219).

Así, el 21 de diciembre, el embajador argentino ante la ONU presentó una nota ante el Consejo de Seguridad, en la que acusaba a Chile de haber ocupado militarmente las islas en conflicto (Tapia, 1997, p. 162).

En diciembre de 1978, las islas y canales australes presentaban el panorama propio de la víspera de la guerra. Las autoridades chilenas habían ocupado las islas en disputa 
con personal militar. Las flotas de guerra de ambos países y sus submarinos estaban desplegados en la zona, entre el estrecho de Magallanes y el mar de Drake, con sus cañones cargados y sus tripulaciones listas para entrar en acción. Empero, una vez más, las expectativas de guerra entre Argentina y Chile se frustraron. Argentina estiró al máximo la tensión, hasta que finalmente alcanzó un nuevo acuerdo con Chile, que aceptó apartarse del laudo arbitral de Isabel II y abrir una nueva negociación. Este acuerdo propuesto por la mediación del papa Juan Pablo II, y aprobado por el plebiscito de 1984 en Argentina, significó una nueva victoria territorial para ésta, que ganó $40 \mathrm{~km}^{2}$ de tierra y $32.500 \mathrm{~km}^{2}$ de mar.

Esta nueva ganancia territorial de Argentina tuvo su contracara en Bolivia. En efecto, al romper relaciones diplomáticas con Chile, el 18 de marzo de 1978, Bolivia dejó caer nuevamente la oferta chilena de salida al mar. Ese día se clausuró la última propuesta formal presentada por Chile para solucionar el enclaustramiento de Bolivia. "Nunca Bolivia estuvo tan cerca del mar y nunca quedó tan lejos, como resultado de su incomprensible política exterior que destruyó una posibilidad que Chile le ofreció considerar". (Lagos, 1981, p. 132).

\section{Conclusiones}

La solución del enclaustramiento de Bolivia requiere, como requisito preliminar, un mejoramiento de las confianzas entre los pueblos y elites de Bolivia y Chile. Es indispensable superar el antagonismo que actualmente enfrenta a ambos países. El discurso nacionalista de historiadores y gobernantes ha terminado por demonizar al otro y crear un sentimiento hostil en los pueblos (Molina, 2014a). Para permitir un reencuentro, es indispensable deponer esas actitudes mediante un análisis crítico de esos discursos.

La incorporación del factor Argentina resulta adecuada para examinar críticamente los discursos nacionalistas que se han cristalizado en las relaciones entre Bolivia y Chile. La mirada, teniendo en consideración a un tercer país, permite tomar distancia de las tradiciones historiográficas de ambas naciones, sin riesgos de ser estigmatizados por traición. A la vez, ese enfoque requiere del análisis autocrítico de la acción del Estado argentino. 
La percepción del otro, en el caso de Bolivia y Chile, se puede mejorar considerablemente con la incorporación del factor Argentina. Sobre todo porque ello permite comprender que el actual enclaustramiento de Bolivia no es resultado únicamente del conflicto con Chile, sino de la sumatoria de muchos otros factores, entre los cuales, la participación de Argentina no fue menor.

Argentina tuvo una participación recurrente en el conflicto entre Bolivia y Chile por el litoral Pacíico, con un patrón constante: la nación rioplatense se acercaba a Bolivia lo suficiente para alarmar a Chile, pero no tanto como para asumir compromisos fuertes. Esta aproximación animaba al país altiplánico a asumir actitudes más audaces frente a Chile. A la vez, ante la amenaza de dos frentes simultáneos, Chile terminaba negociando con Argentina y cediendo territorio. Alcanzado este objetivo, Argentina soltaba la mano a Bolivia, que, una vez abandonado, quedaba en inferioridad de condiciones frente a Chile, el que compensaba con la nación altiplánica las pérdidas sufridas con Argentina.

Este patrón surge de tres circunstancias relativamente homólogas y paralelas. La primera transcurrió entre 1873 y 1881. Como resultado, Argentina anexó la Patagonia (1.000.000 de $\left.\mathrm{km}^{2}\right)$ y Bolivia perdió Atacama $\left(126.000 \mathrm{~km}^{2}\right)$. Argentina incorporó más de 1.000 $\mathrm{km}$ de costas sobre el Atlántico, en tanto que Bolivia perdió cerca de $300 \mathrm{~km}^{2}$ de costas sobre el Pacífico. La segunda oportunidad se verificó entre 1895 y 1904. El resultado fue parecido: Argentina anexó $64.000 \mathrm{~km}^{2}$ de la Puna de Atacama, y Bolivia perdió la salida al mar que le ofreció Chile en mayo de 1895, a cambio del reconocimiento de los territorios ocupados durante la guerra, que incluían el litoral y la Puna de Atacama. Bolivia desperdició esta oportunidad, al ceder, simultáneamente, la Puna de Atacama a Argentina a cambio de Tarija (Protocolo Cano-Rocha). Este doble juego de la diplomacia boliviana generó tensiones en el Cono Sur, desencadenándose una carrera armamentista sin precedentes en la región. Finalmente, Chile evitó la guerra, cediendo el territorio en disputa a un vecino más poderoso, situación que representó una humillación para la cancillería chilena, la que, a su vez, resolvió terminar la negociación con Bolivia e imponer sus razones con la misma razón de la fuerza. El doble juego de los diplomáticos bolivianos de 1895 fue la materia prima de la redacción del "Memorándum König", que condujo al Tratado de 1904 y al enclaustramiento boliviano.

La tercera y última opción se jugó entre 1975 y 1978. Chile volvió a poner frente a Bolivia una salida soberana al mar a través de Charaña. Y una vez más, Argentina entró en el juego: se acercó a Bolivia, lo atrajo a su influencia y lo alentó a desechar la oferta chilena, en función de una eventual aventura bélica. En este contexto, Bolivia dejó caer la 
propuesta de Chile, al romper relaciones diplomáticas el 18 de marzo de 1978, apostando por un juego mayor que nunca ocurrió.

El estudio de varios casos particulares ha permitido conocer, por inducción, las tendencias generales dentro de las cuales se ha desenvuelto la dinámica de las relaciones internacionales en la región. Por lo tanto, no se trata de un hecho aislado, sino de un patrón. Estos casos muestran una predisposición en la política exterior de Bolivia, que se puede sintetizar en los siguientes puntos:

1. Bolivia ha tendido a involucrar a terceros en sus conflictos, en lugar de crear un ambiente de confianza y diálogo constructivo con Chile. Bolivia parece no comprender que esos terceros (en este caso, Argentina, pero también Perú) se acercan a este país y le ofrecen su amistad en función de sus propios intereses. Por ende, cuando el interés de esas naciones implica abandonar a Bolivia a su suerte, lo hacen, una y otra vez.

2. El recurrente discurso de los intelectuales bolivianos, en el sentido de presentar a su país como un actor ingenuo, pacífico y cándido frente a un Chile agresivo y expansionista, es una falacia. En reiteradas oportunidades, Bolivia también asumió una actitud agresiva y llevó adelante políticas activas, tendientes a construir alianzas regionales contra Chile. El Tratado Secreto de 1873 no fue el único caso. Su espíritu volvió a emerger en 1895 con el Protocolo Cano-Rocha y en 1978, en la crisis del Beagle. En estas tres oportunidades, los generales bolivianos calcularon que Argentina entraría en guerra contra Chile.

3. Argentina fue el principal beneficiado de estas maniobras diplomáticas. Sus acercamientos a Bolivia fueron juegos tácticos, tendientes a negociar con Chile desde una posición de fuerza. Como resultado, Argentina logró una importante expansión territorial, que le permitió anexar la Patagonia (1881), buena parte de la Puna (1899) y de los mares australes (1984). El avance territorial argentino fue inversamente proporcional a las pérdidas territoriales de Bolivia. En consecuencia, para revertir la situación del enclaustramiento boliviano sería lógico involucrar también a Argentina; y si Chile tiene que ceder un corredor a Bolivia, y éste no puede retribuir con territorios propios como canje, es posible que se pueda requerir que ese aporte sea realizado por Argentina. 
4. El discurso dominante elaborado en Bolivia, en el sentido de presentarse como una nación víctima de un único y poderoso victimario (Chile), no se ajusta a la realidad histórica. Bolivia es también responsable de su enclaustramiento. No sólo por la guerra del Pacífico, sino también por rechazar de facto las dos ofertas concretas de salida al mar que le ofreció Chile (1895 y 1975), a raíz de las esperanzas despertadas por su eventual alianza con Argentina.

5. Los abogados bolivianos, al fundamentar el caso presentado ante la Corte de La Haya, sostienen que, con sus reiteradas ofertas de ceder una salida soberana al mar, Chile realizó actos jurídicos que modificaron los tratados. Al parecer, ese enfoque no ha examinado con suficiente profundidad las causas por las cuales esas propuestas no se concretaron.

6. La solución del enclaustramiento de Bolivia requiere modificar el Tratado de 1904. No existe autoridad en el mundo (ni el Consejo de Seguridad de la ONU ni la OEA ni otros) con facultades para imponer la modificación de un tratado de límites surgido de una guerra del siglo XIX (Salazar, 2006, p. 110). Tal como sostiene este autor, sólo hay un camino para modificar un tratado de límites: el consenso entre las partes. Para alcanzar este objetivo, la única estrategia posible es la construcción de confianza y cordialidad entre los pueblos. Ello implica comenzar con la superación del relato nacionalista y la actitud hostil que se ha construido durante más de 100 años.

\section{Referencias}

Amunátegui, M. L. (1863). La cuestión de límites entre Chile i Bolivia. Santiago, Chile: Imprenta Nacional.

Arancibia, P. y Bulnes, F. (2014). La escuadra en acción. 1987: el conflicto Chile-Argentina visto a través de sus protagonistas. Santiago, Chile: Catalonia.

Barros, J. M. (1963). Don Estanislao Zeballos y el incidente del "Baltimore”. Mapocho, 1 (2), 218-224. 
Becerra de la Roca, R. (2005). Nulidad de una apropiación chilena. Territorio boliviano entre los paralelos 23 y 24. La Paz, Bolivia: Plural Ediciones.

Benavides, A. (1972). Historia compendiada de la guerra del Pacífico (1879-1884). Santiago, Chile: Editorial Francisco de Aguirre.

Biblioteca Digital de Tratados del Ministerio de Relaciones Exteriores y Culto de Argentina. Comunicado Conjunto Boliviano-Argentino. 21 de abril de 1978, La Paz, Bolivia.

. Convenio de cooperación técnica entre el gobierno de la República Argentina y el gobierno de la República de Bolivia. 2 de abril de 1975, La Paz, Bolivia.

———. Declaración Conjunta Argentino-Boliviana. 16 de marzo de 1976, La Paz, Bolivia.

- - - Declaración Conjunta Argentino-Boliviana. 30 de octubre de 1976, Santa Cruz de la Sierra, Bolivia.

- - - Declaración Conjunta Argentino-Boliviana. 25 de octubre de 1978, Yacuiba, Bolivia.

___ - Memorándum de Coincidencias Argentino-Boliviano. 8 de julio de 1976, Buenos Aires, Argentina.

Brockmann, R. (2014). Bolivia, Chile (Perú) y el mar: entre la obsesión y la indiferencia. En S. Molina, Cuadrar el círculo: las propuestas de solución al conflicto entre Chile y Bolivia (pp. 79-93). Santiago, Chile: LOM Ediciones.

Camilión, O. (2000). Memorias políticas. De Frondizi a Menem (1956-1996). Buenos Aires, Argentina: Planeta.

Carrasco, S. (1990). Historia de las relaciones chileno-bolivianas. Santiago, Chile: Editorial Universitaria.

Corbacho, A., Corigliano, F., Machinandiarena de Devoto, L., González de Oleaga, M. y Tedesco, L. (1999). La Argentina frente a la América del Sur 1881-1930. En A. Cisneros y C. Escudé (dirs.), Colección Historia General de las Relaciones Exteriores de la República Argentina. Tomo VII. Buenos Aires, Argentina: GEL/CARI. 
Durán, P. (2014, 11 de julio). Armando Loayza, ex ministro de RR.EE. de Bolivia: "El gobierno del Presidente Evo Morales estuvo asesorado por un grupo muy radical". La Segunda. Santiago, Chile. Disponible de http://www.lasegunda.com/Noticias/ Politica/2014/07/947954/el-gobierno-del-presidente-evo-morales-estuvo-asesoradopor-un-grupo-muy-radical

El Mercurio (1978, 10 de septiembre). “Guerra Ficción”, El Mercurio. Santiago, Chile.

. (2014, 16 de noviembre). Los chilenos y la demanda boliviana, El Mercurio. Santiago, Chile. Disponible de http://www.elmercurio.com/blogs/2014/11/16/26938/ Los-chilenos-y-la-demanda-boliviana.aspx

Escobari, J. (2013). Historia diplomática de Bolivia. Tomo I. La Paz, Bolivia: Plural.

Espinosa, O. (1958). La posguerra del Pacífico y la Puna de Atacama (1884-1899). Santiago, Chile: Andrés Bello.

Estado Plurinacional de Bolivia. Ministerio de Relaciones Exteriores de Bolivia. 2014. El libro del mar. La Paz, Bolivia: Ministerio de Relaciones Exteriores de Bolivia.

Fernández, S. A. (2014). Promissio est servanda. Lo que se promete se cumple. La reintegración marítima en la política exterior boliviana desde sus inicios hasta la demanda ante La Haya. La Paz, Bolivia: Plural editores.

Fernández, G. (2014). Bolivia y Chile. Callejón sin salida. En S. Molina Monasterios, Cuadrar el círculo: las propuestas de solución al conflicto entre Chile y Bolivia (pp. 47-69). Santiago, Chile: LOM Ediciones.

Forteza, R. y Devés, E. (2006). Diálogos entre Bolivia y Chile: Intelectuales-sociedad civil y diplomacia. Universum, 21 (1), 241-243.

Gutiérrez, A. (2012). La guerra de 1879. La Paz, Bolivia: Librería Editorial GUM.

Jeffs, L. (2014). Chile y Bolivia: reflexiones y desafíos para el siglo XXI. En S. Molina Monasterios, Cuadrar el círculo: las propuestas de solución al conflicto entre Chile y Bolivia (pp. 95-110). Santiago, Chile: LOM Ediciones.

Inarra, L. (2011). Los actos unilaterales del derecho internacional en las relaciones "ChileBolivia”. En E. Zambrana, E. y L. Inarra, Facetas de la controversia con Chile. Memoria 
del Foro Permanente sobre los problemas internacionales de Bolivia "Juan Pereira Fiorilo" (pp. 37-61). La Paz, Bolivia: Grupo Editorial Kipus.

Lacoste, P. (2001). La prensa argentina y el conflicto del Beagle. Boletín de Historia y Geografía, $15,87-116$.

- (2003). La imagen del otro en las relaciones de la Argentina y Chile (1534-2000). Buenos Aires, Argentina: Fondo de Cultura Económica.

Lagos, G. (1981). Historia de las fronteras de Chile. Los tratados de límites con Bolivia. Santiago, Chile: Andrés Bello.

LeShan, L. (1992). La psicología de la guerra. Un estudio de su mística y su locura. Santiago, Chile: Andrés Bello.

Los Andes (1978, 5 de abril). Mendoza, Argentina. "Chile llama a reinscripción masiva de reservistas", p. 2.

. (1978, 7 de abril). Mendoza, Argentina. "Campesinos de la frontera con Chile reclaman al gobierno boliviano armas para defenderse de los atropellos de las tropas chilenas", p. 4.

————. (1978, 20 de abril). Mendoza, Argentina. "Canciller Argentino visita Bolivia”, p. 1.

————. (1978, 21 de abril). Mendoza, Argentina. "Defensa de la integridad territorial”, p. 2.

. (1978, 22 de abril). Mendoza, Argentina. "Bolivia firma convenios con canciller argentino", p. 2.

- - — . (1978, 18 de mayo). Mendoza, Argentina. "Jefe militar boliviano visita la casa de Gobierno de Mendoza", p. 7.

. (1978, 21 de mayo). Mendoza, Argentina. "Canciller boliviano dice que no aceptará la arrogancia chilena”, p. 5 .

————. (1978, 29 de julio). Mendoza, Argentina. "Fabricaciones Militares incrementará producción de material bélico", p. 1.

144 Si Somos Americanos. Revista de Estudios Transfronterizos 
- (1978, 24 de agosto). Mendoza, Argentina. "Sobre el Cono Sur del continente el espectro de la guerra otra vez proyecta su fatídica sombra”, p. 4.

___—. (1978. 14 de septiembre). Mendoza, Argentina. “Guerra Ficción”, p. 1 y 3.

Molina, S. (2014a). Cuadrar el círculo: las propuestas de solución al conflicto entre Chile y Bolivia. Santiago, Chile: LOM Ediciones.

_-_- (2014b). La guerra imaginaria. La construcción del conflicto entre Chile y Bolivia después de la guerra del Pacífico. Tesis para optar al grado de doctor, Universidad de Santiago de Chile (USACH), Santiago.

Muñoz, H. (ed.). (1989). Chile: política exterior para la democracia. Santiago, Chile: Pehuén Editores.

Querejazu, R. (2010). La Guerra del Pacífico. La Paz, Bolivia: Librería Editorial GUM.

Salazar, F. (2006). Bolivia y Chile: desatando nudos. Propuesta de salida al mar para Bolivia basada en el equilibrio de intereses y una nueva racionalidad política. La Paz, Bolivia: Plural Editores.

Tapia, L. A. (1997). Esta noche la guerra. Viña del Mar, Chile: Ediciones de la Universidad Marítima de Chile.

Villalobos, S. (2002). Chile y Perú. La historia que nos une y nos separa 1535-1883. Santiago, Chile: Editorial Universitaria.

Von Clausewitz, K. (1997). De la guerra. Trad. de Francisco Moglia. Buenos Aires, Argentina: Need.

Yrigoyen, Pedro (1921). La Alianza Perú-Boliviano-Argentina y la declaratoria de guerra de Chile. Lima, Perú, Sanmarti y Cia Impresores. 